\title{
Patterns of the Eye Emergencies Referring to the Valiasr Hospital in Birjand, Iran, During the "Nowruz" Holiday 2019
}

\author{
Maliheh Nikandish (iD) ${ }^{1, *}$ \\ ${ }^{1}$ Ophthalmology Department, Birjand University of Medical Sciences, Birjand, Iran \\ "Corresponding author: Ophthalmology Department, Birjand University of Medical Sciences, Valiasr Hospital, Ayatollah Ghaffari Ave., Birjand, Iran. Tel: +98-9153176152, Email: \\ nikandishm@bums.ac.ir
}

Received 2019 July 27; Revised 2019 October 16; Accepted 2019 October 23.

\begin{abstract}
Background: Ocular trauma is an important cause of preventable morbidity, and accounts for half a million cases of monocular blindness worldwide.

Objectives: This study conducted to evaluate the profile of ophthalmic emergencies in a tertiary educational hospital during the "Nowruz" holiday 2019 in Birjand, Iran.

Methods: This cross-sectional survey included all patients visiting the eye-related Emergency Department during "Nowruz" holiday 2019 in the Valiasr Hospital of Birjand. The demographic information and clinical findings, such as presented complaints, the diagnosed eye disease, and the need for hospitalization were recorded. Descriptive statistics (i.e., frequencies and percentages) were calculated.

Results: In the study, 86 patients with a mean age of 42.9 years were enrolled. The number of male subjects was more than female patients (60 (69.8\%) and 26 (30.2\%), respectively). The most presenting complaints were foreign body sensation (34.9\%), followed by red-eye (30.2\%) and ocular pain (11.6\%). The most frequent diagnosis was corneal metal foreign body (24.4\%), followed by conjunctivitis (16.3\%) and ocular trauma (10.5\%). All patients with penetrating injuries were younger than 12 years. Five patients (5.8\%) needed hospitalization and surgery. Approximately, half of the patients were not considered as true emergency case.

Conclusions: In holidays, work-related injuries were the major causes of referral to eye emergency ward with the worse prognosis for children. Therefore, special educational prevention programs to care children should be provided for their parents.
\end{abstract}

Keywords: Ophthalmology, Emergency, Holiday

\section{Background}

Ophthalmic emergencies include conditions that involve sudden threats to the visual system that if left untreated can lead to permanent visual loss and/or severe threats to the visual function of the patients (1). Ocular trauma is an important cause of preventable morbidity and accounts for half a million cases of monocular blindness worldwide. Ocular emergencies need to be addressed as soon as possible, as they can lead to permanent visual loss.

The profile of ocular emergencies is affected by several factors and is varied in different societies. According to Docherty et al., the posterior vitreous detachment was the most common diagnosis, followed by corneal abrasion and retinal detachment at the Vancouver General Hospital per year (2). In a 10 - year retrospective study in New Zealand, the most frequent causes of eye injuries were related to outdoor activities (3). A study in the United States also has reported that the majority of eye injuries occurred at homes, and contusions and abrasions were the most common types of ocular injuries (4). A study conducted in Melbourne has demonstrated a significant relationship between the volume of ophthalmic emergency presentations and daily weather conditions, including temperature, sunshine hours and humidity (5).

Understanding the pattern of emergency patients is helpful for physicians and hospital staff to provide better healthcare to the patients. A limited number of specialists, including ophthalmologists, are available during the Nowruz holiday, which can affect the healthcare service received by the patient through this period. Therefore, the present study was conducted to assess the holiday profile of ocular emergencies in a tertiary educational hospital and the obtained results can be effective to provide a better service during similar periods in the next years. 


\section{Methods}

This cross-sectional survey was performed in the eyerelated emergency department of the Valiasr General Hospital. All patients attended to the eye-related emergency department of Valiasr Hospital during Nowruz holiday (from March 21, 2019, at 8:00 AM to March 26, 2019, at 8 AM) were included in the study. Emergency Department staff included a general practitioner as the triage officer, a trained intern, a nurse who provided around-the-clock care, and one on-call ophthalmologist who visited the patients from 9 AM to 1 PM or any time needed. Also, an ophthalmologic surgery room, with a 24-hour anesthesiology service was available. The final diagnosis of the eye conditions and the need for hospitalization were based on the opinion of the on-call ophthalmologist. Demographic data, including age, sex, the presented complaints, and other variables, such as the diagnosed eye condition and the need for hospitalization were recorded. Corneal metal foreign bodies did not include as the presented complains and was considered as foreign body sensation. Data were collected and descriptive statistics (frequencies and percentages) were calculated and presented in the tables.

\section{Results}

During the study period, 86 patients were referred to the eye-related Emergency Department of Valiasr Hospital. The mean age of the patients was 42.9 years. The number of male subjects was more than female patients (69.8\% and $30.2 \%$, respectively) (Table 1 ).

Table 1. Personal Characteristics of the Patients Visited the Eye-Related Emergency Department of the Valiasr Hospital ${ }^{\mathrm{a}}$

\begin{tabular}{|c|c|}
\hline Demographic Data & Values \\
\hline \multicolumn{2}{|l|}{ Gender } \\
\hline Male & $60(69.8)$ \\
\hline Female & $26(30.2)$ \\
\hline \multicolumn{2}{|l|}{ Age groups, y } \\
\hline Children (0-12) & $5(5.8)$ \\
\hline Young adult $(12-40)$ & $43(50)$ \\
\hline Middle age (40 - 60) & $22(25.6)$ \\
\hline Old age (60 - 85) & $16(18.6)$ \\
\hline
\end{tabular}

${ }^{\mathrm{a}}$ Values are expressed as No. (\%).

The majority of patients ( $90.5 \%$ ) were self-referred to the emergency department. The most common complaint was foreign body sensation in 30 patients (34.9\%). Red-eye and ocular pain were the next common complaints found in $26(30.2 \%)$ and 10 (11.6\%) patients, respectively (Table 2 ).
Table 2. The Presenting Complains of Patients Visited the Eye-Related Emergency Department of the Valiasr Hospital ${ }^{\mathrm{a}}$

\begin{tabular}{|lc}
\hline Presenting Complain & Values \\
\hline Foreign body sensation & $30(34.9)$ \\
\hline Red-eye & $26(30.2)$ \\
\hline Painful eye & $10(11.6)$ \\
\hline Trauma & $9(10.5)$ \\
\hline Reduced vision & $5(5.8)$ \\
\hline Photophobia & $5(5.8)$ \\
\hline Floater & $1(1.2)$ \\
\hline Total & $86(100)$ \\
\hline
\end{tabular}

${ }^{\mathrm{a}}$ Values are expressed as No. (\%).

Table 3 shows the most common diagnoses among patients. The corneal metal foreign body had the highest incidence rate (24.4\%), followed by conjunctivitis (16.3\%). Five patients $(5.8 \%)$ required hospitalization and surgery, of whom three patients had globe rupture, one patient had malignant glaucoma, and one case had lid laceration. Presenting complains of trauma were found in 9 patients, which included the following diagnoses: globe rupture in three patients, hyphema in two patients, one lid laceration, one corneal abrasion, one periorbital hemorrhage, and one chemical burn. By including corneal metal foreign body in the trauma category, the most common manifestation was trauma in our patients. Among the other diagnostic groups lid laceration, recurrent epithelial erosion, anterior uveitis, periorbital hemorrhage, episcleritis, traumatic corneal abrasion, branch retinal artery occlusion, refractive error, periorbital cellulitis, superficial punctate keratopathy, herpes zoster ophthalmicus, malignant glaucoma, and fourth nerve palsy that presented with blurred near vision can be mentioned (each contained only one patient).

\section{Discussion}

Several studies have investigated the pattern of referrals to the eye-related emergency department in different periods and communities. To our knowledge, this was the first study that emphasized on referrals to the eye-related emergency department during the "Nowruz" holiday in Iran. Another specific aspect of the survey is that no other specialized ophthalmology services were provided in the South Khorasan province during the study period.

A previous study in New Zealand showed that the main presenting symptoms of the patients attending eyerelated emergency departments in a major public tertiary 
Table 3. The Most Common Diagnoses Among Patients Visited the Eye-Related Emergency Department of the Valiasr Hospital ${ }^{\mathrm{a}}$

\begin{tabular}{|lc|}
\hline Diagnosis & Values \\
\hline Subconjunctival hemorrhage & $8(9.3)$ \\
\hline Conjunctivitis & $14(16.3)$ \\
\hline Corneal ulcer & $3(3.5)$ \\
\hline Chemical burn & $1(1.2)$ \\
\hline Corneal metal foreign body & $21(24.4)$ \\
\hline Hordeolum/chalazion & $2(2.3)$ \\
\hline Dry eye & $9(10.5)$ \\
\hline Pinguecula & $3(3.5)$ \\
\hline Ultraviolet keratitis & $3(3.5)$ \\
\hline Globe rupture & $3(3.5)$ \\
\hline Hyphema & $2(2.3)$ \\
\hline Vitreous hemorrhage & $2(2.3)$ \\
\hline Others & 15 \\
\hline Total & 86 \\
\hline
\end{tabular}

${ }^{\mathrm{a}}$ Values are expressed as No. (\%).

teaching hospital were the pain, red-eye, and reduced vision and major diagnoses were trauma, uveitis and adenoviral keratoconjunctivitis (6). A study in West Africa showed three consecutive cases of ocular injuries following banger explosives that presented during the New Year festival. Two patients ended up with the irreversible loss of vision (7).

A one-year study conducted in Farabi Hospital, Iran showed the work-related injuries as the major causes of eye emergencies. Open globe injuries comprised a small proportion of eye injuries (5.9\%) and among the nontraumatic reasons, eye infection was the most common(8).

A cross-sectional study in Kashan, Iran investigated the characteristics of hospital admissions for eye trauma through three years and showed that approximately $38.5 \%$ of the eye traumas were occurred at the workplace. The subjects' age range was 20 - 39 years and most of them had penetrating injuries and were treated surgically (9). In terms of age, these results are not consistent with our findings, as the patients with penetrating injuries were younger ( $<12$ years).

A study from Northern Taiwan evaluating the etiologic factors of major ocular trauma in a tertiary hospital showed that the domestic-related injury and occupational injuries were the predominant causes among patients younger than 18-year-old and those aged above 18 years, respectively (10). In our study, three patients, including two male and one female patient had globe rupture during five days (3.5\%). Although the study was done after the "Fireworks Wednesday" ceremony (causing fireworkrelated injuries), one of the cases with globe rupture was related to the cracker that accidentally had found on the street by other people and the patient was a bystander. The other two patients were younger than 7 years and showed accidental injuries at home; one of them was 3 years old with corneoscleral rupture as well as iris, lens and vitreous prolapse. According to the ocular trauma score, which is used to predict the visual outcome of patients after openglobe ocular trauma, unfortunately, our patients scored 1 , indicating the most severe injury and worst prognosis at 6 months follow-up $(11,12)$.

An analytic study conducted in a general hospital in Sao Paulo evaluated the treatment complexity level of patients visited the eye-related emergency department during a typical week, and showed that the most frequent diagnoses were ocular inflammation and infection, followed by ocular trauma, particularly foreign bodies on the cornea (13). This study is similar to ours regarding the duration of survey, however our study included five days of the "Nowruz" holiday. Therefore, the profile of our patients was different from this study. Although the current study was done during vacation days, we showed the corneal foreign body as the most common diagnosis, followed by conjunctivitis. This was contrary to our expectations that workplace trauma can exhibit a lower frequency, due to the vacation time.

A study that evaluated ocular trauma during a 7-day Eid al-Fitr holiday in Kuwait reported that toy-gun injuries were occurred in 19 children with the mean age of 7.8 years. The patients only had anterior segment involvement, with no evidence of posterior segment trauma or ruptured globe (14). Compared to this study, our patients had a significantly worse prognosis. Glaucoma was diagnosed in one patient that was pseudophakic malignant glaucoma and the subject underwent peripheral iridectomy, capsulo-hyaloidectomy, and anterior vitrectomy after treatment failure. Another patient that needed surgery was a 4 years old boy with lid laceration due to the accidental trauma.

Dry eye disease (DED) was seen in $10.5 \%$ of our patients with presenting complains of foreign body sensation that met the criteria of DED proposed by the Japanese Dry Eye Society, including dry eye and decreased tear breakup time (15).

Two cases were referred from other cities of the province using ambulance, including a patient with chemical burn and another with traumatic periorbital hematoma. Although telephone counseling was provided, it, in turn, led to an unnecessary action and also caused ad- 
ditional costs. It is largely related to the concerns related to the eye intervention among general practitioners, which can be corrected by modification of the general medical training curriculum.

Approximately, half of the patients were not considered as a true emergency case and could have been diagnosed and treated by trained general practitioners. We found the worst prognosis in the age group of younger than 7 years old. These findings indicated that parents should be elaborated more efficiently in care and observation of their children at home and during holidays. The educational system is advised to discuss these points with families during holidays.

In conclusion, the pattern of eye emergencies during the "Nowruz" holiday showed work-related injuries as the major cause of eye emergencies. Giving the severity of these injuries, children need special care, and also preventive education should be provided for their parents. The presence of a trained physician in the primary and secondary healthcare centers can prevent unnecessary referrals.

\section{Footnotes}

Conflict of Interests: The author declares that there is no conflict of interests.

Funding/Support: The present study was not financially supported.

\section{References}

1. Alabbasi OM, Al-Barry M, Albasri RF, Khashim HF, Aloufi MM, Abdulaal MF, et al. Patterns of ophthalmic emergencies presenting to a referral hospital in Medina city, Saudi Arabia. Saudi J Ophthalmol. 2017;31(4):243-6. doi: 10.1016/j.sjopt.2016.03.001. [PubMed: 29234226]. [PubMed Central: PMC5717507].

2. Docherty G, Hwang J, Yang M, Eadie B, Clapson K, Siever J, et al. Prospective analysis of emergency ophthalmic referrals in a Canadian tertiary teaching hospital. Can J Ophthalmol. 2018;53(5):497-502. doi:10.1016/j.jcjo.2018.01.008. [PubMed:30340718].
3. Pandita A, Merriman M. Ocular trauma epidemiology: 10-year retrospective study. N Z Med J. 2012;125(1348):61-9. [PubMed: 22282278].

4. McGwin GJ, Owsley C. Incidence of emergency department-treated eye injury in the United States. Arch Ophthalmol. 2005;123(5):662-6. doi: 10.1001/archopht.123.5.662. [PubMed: 15883286].

5. Young TK, Ruddle JB, Crock C, Hewitt AW. Influence of weather conditions on ophthalmic emergency presentations. Clin Exp Ophthalmol. 2012;40(3):322-3. doi: 10.1111/j.1442-9071.2011.02587.x. [PubMed: 21631686].

6. Osmani F, Hajizadeh E, Rasekhi A. Association between multiple recurrent events with multivariate modeling: A Retrospective cohort study. J Res Health Sci. 2018;18(4). e00433. [PubMed: 30728319].

7. Perumal D, Niederer R, Raynel S, McGhee CN. Patterns of ophthalmic referral and emergency presentations to an acute tertiary eye service in New Zealand. N Z Med J. 2011;124(1340):35-47. [PubMed: 21952383].

8. Adeoti CO, Isawumi MA, Onakpoya OH, Agbeleye DS. Banger-related ocular injuries during new year festivities in Osogbo, SW Nigeria. EthiopJHealth Sci.2015;25(2):185-8. doi: 10.4314/ejhs.v25i2.12. [PubMed: 26124627]. [PubMed Central: PMC4478271].

9. Jafari AK, Bozorgui S, Shahverdi N, Ameri A, Akbari MR, Salmasian H. Different causes of referral to ophthalmology emergency room. J Emerg Trauma Shock. 2012;5(1):16-22. doi: 10.4103/0974-2700.93104. [PubMed: 22416149]. [PubMed Central: PMC3299147].

10. Movahedinejad T, Adib-Hajbaghery M, Zahedi MR. A Study on hospital admissions for eye trauma in Kashan, Iran. Trauma Mon. 2016;21(2) e28073. doi: 10.5812/traumamon.28073. [PubMed: 27626013]. [PubMed Central: PMC5003473].

11. Chien KH, Chang HC, Lu DW. Open globe injury in a tertiary hospital in Northern Taiwan: A 10-year review. J Med Sci. 2016;36(4):131. doi: 10.4103/1011-4564.188893.

12. Scott R. The ocular trauma score. Community Eye Health. 2015;28(91):44-5. [PubMed: 26989308]. [PubMed Central: PMC4790158].

13. Carvalho Rde S, Jose NK. Ophthalmology emergency room at the University of Sao Paulo General Hospital: A tertiary hospital providing primary and secondary level care. Clinics (Sao Paulo). 2007;62(3):3018. doi: 10.1590/s1807-59322007000300015. [PubMed: 17589671].

14. Bouhaimed M, Alwohaib M, Alabdulrazzaq S, Jasem M. Toy gun ocular injuries associated with festive holidays in Kuwait. Graefes Arch Clin Exp Ophthalmol. 2009;247(4):463-7. doi: 10.1007/s00417-008-0956-7. [PubMed: 18843497].

15. Shimazaki J. Definition and diagnostic criteria of dry eye disease: Historical overview and future directions. Invest Ophthalmol Vis Sci. 2018;59(14):DES7-12. doi: 10.1167/iovs.17-23475. [PubMed: 30481800]. 